\title{
Development of Methods of Innovative Projects' Management in Developer Organizations
}

\author{
Oksana Papelniuk ${ }^{1, *}$ \\ ${ }^{1}$ Moscow State University of Civil Engineering,26, Yaroslavskoye shosse, Moscow,129337, Russia
}

\begin{abstract}
In article the author studies the conceptual scheme of life cycle of innovative developer project and offers methods of innovative projects' management according to the stages of its lifecycle. The author describes algorithm of the organization of management system of innovative projects in the developer organization representing set of stages and methods. The offered algorithm allows developer organizations achieve one of the main of their objectives, which is the creation of a special environment of comfortable accommodation with the emphasis on ecological compatibility and energy efficiency.
\end{abstract}

\section{Introduction}

Creation of a special environment of comfortable accommodation with the emphasis on ecological compatibility and energy efficiency is impossible without innovations and becomes one of the main objectives of developer. Innovative development is closely connected not only with the newest technologies of construction, but also with management of the territories of complex building. Nowadays project methods of management acquire special relevance in construction and development, and in particular, in innovative development.

All cycle of development and implementation of management decisions on implementation of an innovative product in the developer organization needs to be considered as project management. Therefore in case of development and projects implementation on implementation of an innovative product in the construction and developer organization implementation processes of such projects shall include everything or the most part of stages of project lifecycle. And on the commonly accepted classification there is a lot of them that can be traced according to the conceptual scheme of project lifecycle provided on fig. 1 [1].

Analyzing the data provided on the drawing it is possible to conclude that not all stages of project lifecycle in case of implementation of an innovative product and, first of all, new construction materials shall be included in group for compulsory use. In some cases it is possible to exclude stages of operation and support of the project [2].

'Corresponding author: oksana-17@mail.ru 


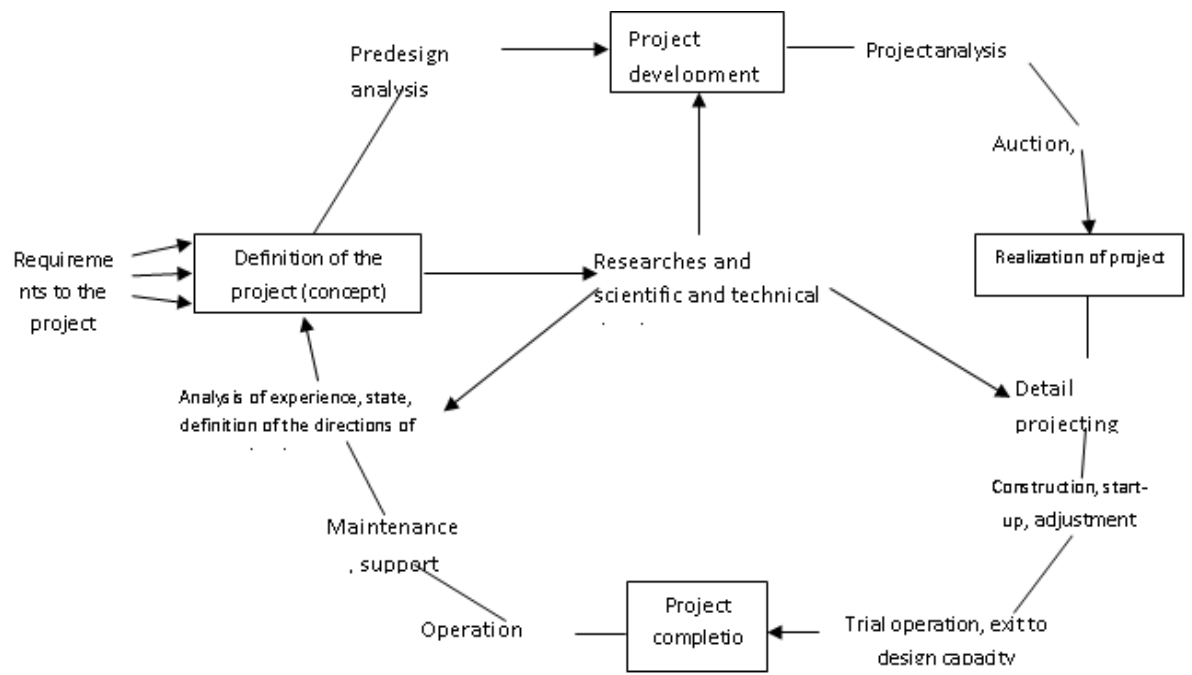

Fig. 1.Conceptual scheme of life cycle of the project

\section{Methods}

The choice of creation of an organizational management system innovative projects in the developer organization is directly influenced by two groups of the factors which are prerequisites to implementation of innovative activities in a construction and development: internal and external. Schematically their content can be provided as follows (fig.2).

Internal factors are implied as the problems arising in the organization and requiring the solution by carrying out these or those innovations. External prerequisites are understood as any situations developing in external entrepreneurial environment, leading to adaptation of market subjects to new conditions also by means of implementation of innovations $[3,4]$.

The solution of the arising problems in all cases is connected taking into account scientific and technical base, a financial position, creative activity of personnel and achievements in the production sphere.

Project management is the difficult system including an object and a subject of management. In this system two groups of processes are implemented: 1) the project oriented processes. They are connected with object of project management or the project, are carried out by contractors of the project; 2) processes of management of the project which are connected with the subject of project management or a project management team and its activities by description, to planning, the organization and coordination of works in the project for providing a successful completion of the project.

In the basic plan project management has eight integrated directions which from line items of system approach to management it is necessary to call project management subsystems. Treat them: management of content; management of duration; management of cost; quality management; personnel management, or human resources management; management of material logistics, or resource management (material); management of communications (information resources); risk management $[5,6]$.

Each of the listed subsystems, though differently, but surely interacts with Basic Elements of a project management system. 


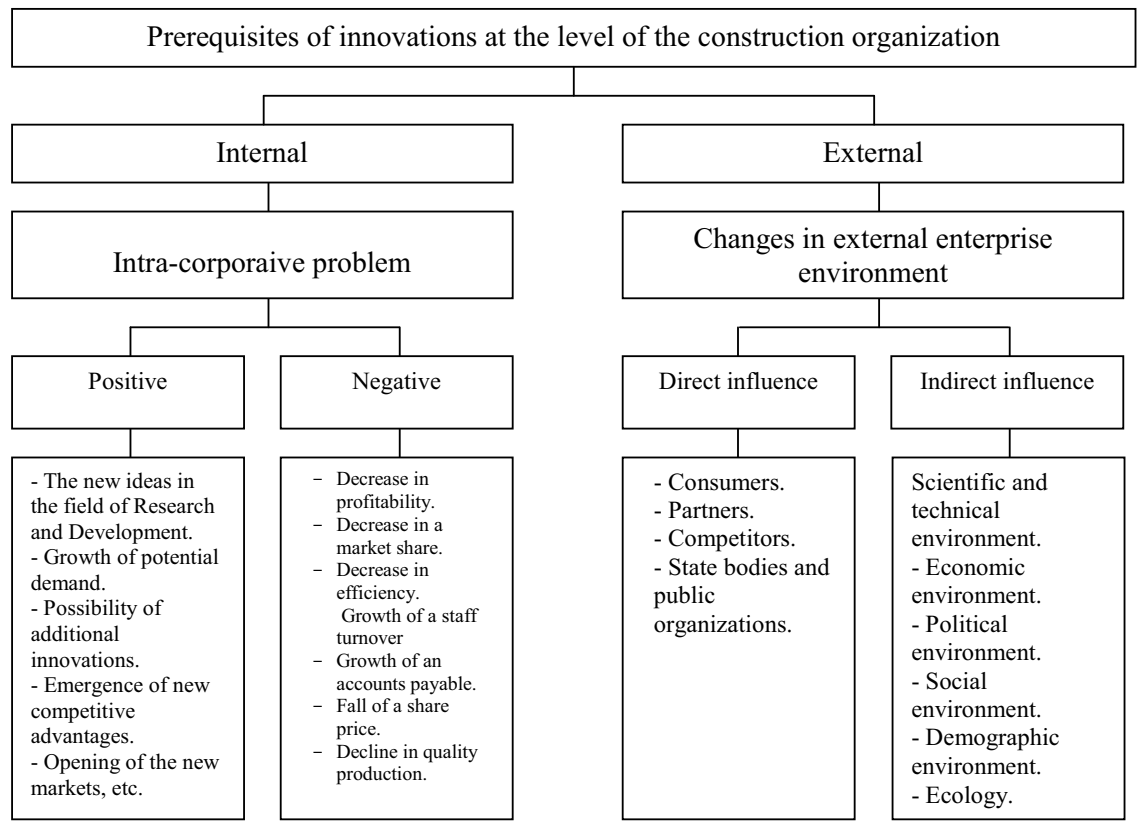

Fig. 2. Prerequisites of innovative activities at the level of the developer organization

In initial system (management of content) the structure and structure of works, resources, results and risks is in essence determined. In a subsystem of management works, resources, results and risks are considered, the management of which predetermines project duration. Management of cost and quality management are directed to all Basic Elements of the project [7].

Personnel management, management of material resources and management of communications, first of all, is directed to the corresponding types of resources (human, material and information). Risk management is directed to optimization of interaction of all project with the environment.

It is visible that in each of the listed subsystems it is necessary to develop the methodical approaches and procedures for project management.

Let's stop on environmental issues and project participants.

The project is the open system interacting with the environment. The environment of the innovative project is understood as set of the factors and objects which are directly not taking part in the project, but influencing the project and performing interaction with the project and its separate elements. Usually allocate a direct environment of the project, i.e. the factors and objects interacting with the project directly and a distant environment of the project, i.e. the factors and objects interacting with the project by means of other factors and objects which are usually entering a direct environment $[8,9]$.

From a large number of project participants who are of interest in this direction it is necessary to allocate the initiator, the customer, the investor, the project manager (project manager), a project team, the consumer of results of project implementation.

The direct consumer of the constructed object substantially predetermines requirements to future project deliverable on implementation of an innovative product in the construction organization.

But, the most active project participants, nevertheless, are: project manager and project team. The main amount of works on development and project implementation is assigned to 
their shoulders. To the project manager appropriate authority is delegated, and he bears responsibility to the customer for goal achievement of the project. The project team directly carries out the main amount of work on development and project implementation[10].

One of the most important purposes of these researches is development of organizational management system innovative projects in the construction organization which would include creation of an organizational structure at the level of the construction organization, the choice of methods and controlling mechanisms processes of development and implementation of innovative projects.

\section{Results}

Achievement of an effective objective is recommended to be carried out step by step. Content and a priority of stages are stated below.

1. It is recommended to allocate as the first stage works on establishment of restrictions which need to be considered on a solution of all subsequent tasks on development of all system of innovative management in the developer organizations. After the carried-out analysis the number of such restrictions included the following:

- it is established that the organizational system of innovative management in the developer organization is developed for the first time as now in most the developer organizations there are no such systems, though separate innovative products take root into practice;

- as the main innovative product in such developer organization there will be a new construction material.

2. The head of the construction organization independently or with involvement of other specialists both the organization, and third-party shall be determined - whether it is worth developing work on creation of all system of innovative management for implementation of several innovative products or will be limited to development only of limited number (1-3) of projects, though on each of them the project management system shall be constructed.

In that and in other case it is necessary to carry out initiation of innovative projects regarding their basic sales opportunity in the developer organization.

As at this stage it is desirable to execute an efficiency evaluation of application of separate specific innovative projects. But it at this stage in the majority can lead to unjustified costs and extra time will be required.

Therefore it is possible to be limited to carrying out express assessment of investment offers on each innovative project with completion of which there will be corresponding declarations. In less detail it can be made by collection and preprocessing of information using new innovative products and first of all construction materials and mainly obtaining information in base the Internet, in other printed materials, booklets at exhibitions, etc.

By the final stage of work on initiation of innovative projects the list (from one to several) innovative projects which can be realized in the construction organization shall be constituted.

3. The head of the construction organization by the order establishes an order of assessment works of efficiency and assessment of sales opportunity of the innovative projects initiated to application. Under the same order in the construction organization teams are formed and heads on each project or on group of innovative projects affirm. Before evaluating cost efficiency of each innovative draft of the command on them can be small as at this stage there is no clarity about feasibility of implementation of each of the selected versions of innovative projects yet. On management of each innovative project join in team's line-up both specialists of the construction organization, and specialists from other accounting entities. 
4. Specialists of a project team carry out complete assessment work of efficiency of each innovative project. In case of such assessment it is necessary not only to reveal economic feasibility of implementation of each innovative project, but also to reveal technical capabilities of its implementation and first of all, to estimate the technical base and possibilities of its filling in case of need.

5. The additional order the head of the organization establishes final team's line-up on each innovative project with determination of some general installations approved to execution on the organization of implementation of each innovative project. In the order some restrictions on levels and a date of completion of an expense of means on each project are also given. In such order there can be instructions for forms, levels and for limits of payment of third-party specialists if they are attracted in team of the innovative project.

6. The most responsible and difficult for team of each innovative project is development of the program for projects implementation and in completion to carry out it coordination and approval of programs. Programs for each innovative project, for some line items shall be approved and arranged in the form of the supplementary agreement with the customer on construction of facilities. At the same time the construction organization and the customer can change an object construction cost which was already determined in the contract agreement.

7. The team of the innovative project prepares and approves offers on possible change of an organizational structure in the developer organization. It or liquidation of some production or managerial division, or reshaping of some division of a management structure of the construction organization.

The final decision at the choice of this or that option shall belong to a management of the construction organization and is formalized in the order on the construction organization.

8. To develop specially in the form of the separate block of management decisions for implementation of such obligatory management function by the project as stimulation isn't recommended to be carried out. This work can be provided in the managerial program for each innovative project. The project team in this case shall carry out work on control of execution of the program or earn additionally offers on a certain change of provisions of the program.

9. Control teams innovative projects prepare, claim and provide execution of possible changes in programs of implementation of investment projects. It will be in essence one of options of execution of functions of the project as regulation.

10. Management function execution by the project as exercises control both a control team the innovative project, and separate functional divisions or individuals from heads in the developer organization. It shall be fixed by the order of the head of the organization.

\section{Discussion}

For carrying out work on completion of innovative projects and including execution of the relevant acts it is recommended not to create the special commission. This work can be performed within work of state commissions on acceptance of the constructed objects in operation. However, when the innovative project comes to the end before construction of an object, by order of the head of the developer organization the special commission for registration on closing of each innovative project shall be created. Such commissions shall include both specialists of the developer organization, and specialists from the customer, the project organizations and representatives of local administrative-territorial educations. In certain cases it is necessary to include in such commissions both some other specialists and first of all representatives of subjects in whom the new innovative project when they 
implement the new construction material which is already used in others developer the organizations was created.

After completion of each innovative project the head of the developer organization by the decision (order) dismisses line-up of the team of each innovative project or will change their activities for management of other innovative projects which are again approved to implementation.

\section{Conclusion}

Thus, the system of innovative management is implemented by the organization to provide fixed nature of management of innovative activities, to organize and coordinate works within management of innovative activities, to exercise control and the analysis of results and effect of implementation of innovative activities, in other words, general managerial tasks. Along with the solution of general also specific managerial problems as the entity needs to plan innovations are solved, to range them in the directions of the activities, to perform risk analysis, and also to determine methods and the directions of their minimization, to manage innovative projects, to research the markets of resources and to find suppliers and customers.

\section{References}

1. L.Ustinovicius, R.Rasiulis ,L.Nazarko , T.Vilutienè , M.Reizgevicius. Procedia Engineering, 122,166-171 (2015)

2. I.G. Lukmanova, A.G. Korolyov, E.V. Nezhnikova, Project Management, MGSU,(2013)

3. M. T. Hannan. Change Management: a reader.Publishing House of the Executive. wk. Management, St. Petersburg, 2010.

4. A.D. Ishkov, M.Yu. Mishlanova, K.P. Grabovyi. International Journal of Applied Engineering Research. T. 11. № 3. (1676-1679), 2016.

5. A.C. Aurora Teixeira, S.S. AnabelaQueirós. Research Policy, 45, 1636-1648 (2016)

6. Sborshchikov S.B., Lazareva N.V., ZharovYa.V. Vestnik MGSU,6, 165-171 (2014)

7. D.N. Silka, Life Science Journal, 7, 310-313 (2014)

8. P.G. Grabovyi, I.P. Avilova, A.V. Sharapova, Life Science Journal, 11, 1097 (2014)

9. V. Khmel, S. Zhao. IATSS Research, 39, (2), 138-145 (2016)

10. E.K. Chirkunova, E.E. Kireeva, A.D. Kornilova, J.S. Pschenichnikova. Procedia Engineering, 153, 112-117 (2016) 